\title{
Percutaneous Coronary Intervention Compared to Coronary Artery Bypass Grafting in Patients with Non-ST-Elevation Acute Coronary Syndrome - A Systematic Review and Meta-Analysis
}

\author{
Hristo Kirov \\ Department of Cardiothoracic Surgery, Friedrich-Schiller-University Jena \\ Tulio Caldonazo \\ Department of Cardiothoracic Surgery, Friedrich-Schiller-University Jena \\ Mohamed Rahouma \\ Department of Cardiothoracic Surgery at New York Presbyterian, Weill Cornell Medical Center \\ Bryce Robinson \\ Department of Cardiothoracic Surgery at New York Presbyterian, Weill Cornell Medical Center \\ Michelle Demetres \\ Samuel J. Wood Library and C.V. Starr Biomedical Information Center, Weill Cornell Medicine \\ Patrick Serruys \\ Department of Cardiology, National University of Ireland, Galway (NUIG), Galway, Ireland and CORRIB Corelab and Center for Research and Imaging \\ Giuseppe Biondi-Zoccai \\ Department of Medico-Surgical Sciences and Biotechnologies, Sapienza University of Rome, Latina \\ Mario Gaudino \\ Department of Cardiothoracic Surgery at New York Presbyterian, Weill Cornell Medical Center \\ Torsten Doenst ( $\nabla$ doenst@med.uni-jena.de ) \\ Department of Cardiothoracic Surgery, Friedrich-Schiller-University Jena
}

\section{Research Article}

Keywords: coronary artery bypass grafting, percutaneous coronary intervention, acute coronary syn-drome, non-ST-elevation

Posted Date: September 29th, 2021

DOI: https://doi.org/10.21203/rs.3.rs-909265/v1

License: (c) (i) This work is licensed under a Creative Commons Attribution 4.0 International License. Read Full License

Version of Record: A version of this preprint was published at Scientific Reports on March 24th, 2022. See the published version at https://doi.org/10.1038/s41598-022-09158-0. 


\section{Abstract}

Objectives: Non-ST-elevation acute coronary syndrome (NSTE-ACS) affects millions of patients. Although an invasive strategy can improve survival, the optimal treatment (i.e., percutaneous coronary intervention $[\mathrm{PCI}]$ or coronary artery bypass grafting $[\mathrm{CABG}]$ ) is not clear. We performed a metaanalysis of studies reporting outcomes between PCI and CABG in patients with NSTE-ACS.

Methods: MEDLINE, EMBASE and Cochrane Library were assessed. The primary outcome was long-term mortality. Inverse variance method and random model were performed.

Results: We identified 13 observational studies (48,891 patients). No significant difference was found in the primary endpoint (CABG vs. PCl, incidence rate ratio [IRR] $=0.93,95 \%$ confidence interval $[\mathrm{Cl}] 0.70 ; 1.23)$. CABG was associated with lower long-term major adverse cardiovascular events (MACE) (IRR= $0.64,95 \% \mathrm{Cl} 0.54 ; 0.76)$ and lower long-term re-revascularization (IRR= $0.37,95 \% \mathrm{Cl} 0.30 ; 0.47)$. There was no significant difference in long-term myocardial infarction (CABG vs. $\mathrm{PCl}, \mathrm{IRR}=0.96,95 \% \mathrm{Cl} 0.50 ; 1.84$ ) and peri-operative mortality (CABG vs. PCl, odds ratio $[\mathrm{OR}]=1.36,95 \% \mathrm{Cl} 0.94 ; 1.95)$.

Conclusion: For the treatment of NSTE-ACS, CABG and PCl are associated with similar rates of long-term mortality and myocardial infarction. CABG is associated with lower rates of long-term MACE and re-revascularization. Randomized comparisons in this setting are necessary.

\section{Introduction}

Non-ST-elevation acute coronary syndrome (NSTE-ACS) represents a large proportion of patients with acute coronary syndromes (ACS) impacting millions of patients worldwide [1, 2].

Recently, the percentage of patients presenting with non-ST-elevation myocardial infarction (NSTEMI) has increased in both Europe and United States [1, 2]. Although a routine invasive strategy in NSTE-ACS may improve long-term survival and reduce late myocardial infarction [3], the optimal treatment method remains controversial. Specifically, it remains unclear as to whether percutaneous coronary intervention $(\mathrm{PCl})$ or coronary artery bypass grafting (CABG) provide better long-term outcomes [4].

To date, there is no randomized comparison of PCl vs. CABG surgery in the specific setting of NSTE-ACS. While there have been a number of nonrandomized studies published, their results have been inconclusive. Additionally, no systematic review and meta-analysis addressing this topic exists in the literature.

In this analysis we set out to systematically review the literature on the impact of the treatment modality on clinical outcome in NSTE-ACS.

\section{Methods}

This analysis was prospectively registered on the International Prospective Register of Systematic Reviews in Health and Social Care (PROSPERO, ID number CRD42020214423). Ethical and internal review board approval was not required for this analysis as no human or animal subjects were involved.

\section{Search strategy}

A medical librarian (MD) performed a comprehensive literature search to identify contemporary studies comparing outcomes in patients with NSTEACS (unstable angina pectoris [UAP] and non-ST-elevation myocardial infarction [NSTEMI]) who underwent either PCI or CABG. Searches were run on October 19, 2020 in the following databases: Ovid MEDLINE® (ALL; 2008 to present); Ovid EMBASE (1974 to present); and The Cochrane Library (Wiley). The search strategy for Ovid MEDLINE is available in Supplementary Table 1.

\section{Study selection and eligibility criteria}

The study selection followed the Preferred Reporting Items for Systematic Reviews and Meta-Analyses (PRISMA) strategy [5]. After de-duplication, records were screened by two independent reviewers (TC and HK). Any discrepancies and disagreements were resolved by a third author (TD). All titles and abstracts were reviewed against pre-defined inclusion and exclusion criteria. Studies were considered for inclusion if they were written in English, reported direct comparison between PCI patients and CABG patients and had at least 1 outcome of interest reported. Studies evaluating refractory angina, chronic coronary disease, conference abstracts, proceedings and case reports were excluded.

Following the first round of screening, full text was pulled for selected studies for a second round of eligibility screening. Reference lists for articles in these selected studies were also searched for any relevant articles not captured by the original search strategy.

\section{Data abstraction and quality assessment}

The data extraction and the quality assessment were performed independently by two different investigators (TC and HK) and verified by a third investigator (TD) for accuracy. The following variables were extracted: age, sex, left ventricular ejection fraction, hypertension, diabetes, smoking 
status, prior cerebrovascular accident, prior myocardial infarction, prior percutaneous coronary intervention and number of vessels addressed (1, 2 or 3$)$.

Risk of bias was assessed based on Newcastle-Ottawa assessment scale (Supplementary Table 2) [6].

\section{Outcomes and effect summary}

The primary outcome was long-term mortality (> 6 months). Mean follow up by study is summarized in Table 1.

Secondary outcomes were long-term major adverse cardiovascular events (defined in Supplementary Table 3), long-term re-revascularization, longterm myocardial infarction and peri-operative mortality (in-hospital and 30-day events). For the primary outcome, a sensitivity analysis comparing adjusted and low risk of bias studies vs. unadjusted studies was also performed.

\section{Data analysis}

Peri-operative binary outcomes were reported as odds ratios (OR) while long-term outcomes, were reported as incidence rate ratio (IRR); for both estimates the generic inverse variance method was used and 95\% confidence intervals (Cls) were also presented.

Random effect meta-analysis was performed using "metafor" and "meta" package [7, 8]. CABG was the reference for all pairwise comparisons. Heterogeneity was reported as low $\left(\mathrm{I}^{2}=0-25 \%\right)$, moderate $\left(\mathrm{I}^{2}=26-50 \%\right)$, or high $\left(\mathrm{I}^{2}>50 \%\right)$ [9]. Leave-one-out analysis for the primary outcome was performed to assess the robustness of the obtained estimate. Meta-regression was used to explore the effects of: year of publication, mean followup time, age, sex, left ventricular ejection fraction, hypertension, diabetes, smoking status, prior cerebrovascular accident, prior myocardial infarction, prior percutaneous coronary intervention and number of vessels addressed $(1,2$ or 3$)$ on the IRR of the primary outcome.

Statistical significance was set at the 2-tailed 0.05 level, without multiplicity adjustments. All statistical analyses were performed using R (version 3.3.3, R Project for Statistical Computing) within RStudio.

\section{Results}

\section{Description of included studies}

A total of 7,520 records were identified through database searching. After duplicate records were removed, 5,927 citations were retrieved and their titles and abstracts were screened; 13 studies were included in the final analysis, with a total of 48,891 patients. The full PRISMA flow diagram outlining the study selection process is available in Fig. $1[5,10,11]$. A complete list of studies included in the final analysis is presented in Table 1.

All studies were observational: 5 of them were unadjusted and 8 adjusted (adjustment details are shown in Table 1). Ten studies were multicenter; 3 originated from the United States, 2 from Israel, 1 each from Netherlands, Australia, Germany, Saudi Arabia, Poland, South Korea, Portugal and China.

The number of patients in each study ranged from 450 to 15,281. The mean age ranged from 56.1 to 75 years. The percentage of female sex in each study ranged from 18.0 to $43.5 \%$. The prevalence of hypertension ranged from 43.0 to $87.3 \%$, diabetes from 22.0 to $100.0 \%$, smoking from 5.0 to $74.0 \%$, prior cerebrovascular accident from 2.1 to $11.9 \%$ and prior myocardial infarction from 21.3 to $100.0 \%$. The percentage of 1 -vessel disease ranged from 0.0 to $47.2 \%$, 2-vessels from $9.3 \%$ to $67.0 \%$ and 3-vesels from 16.3 to $100.0 \%$ (Supplementary Table 4).

\section{Primary outcome}

Detailed results of the meta-analysis are outlined in Graphical Abstract and summarized in Table 2.

No significant difference between the groups was found in long-term mortality (IRR $=0.93,95 \% \mathrm{Cl} 0.70 ; 1.23, \mathrm{p}=0.83$, Fig. 2). This finding was confirmed in the sensitivity analysis comparing adjusted and low risk of bias studies vs. unadjusted studies (p-interaction $=0.58$, Supplementary Fig. 1).

Leave-one-out analysis confirmed the solidity of the pooled estimate (Supplementary Fig. 2). Funnel plot did not demonstrate evidence of publication bias (Supplementary Fig. 3).

\section{Secondary outcomes}

CABG was associated with lower long-term major adverse cardiovascular events (IRR $=0.64,95 \% \mathrm{Cl} 0.54 ; 0.76, \mathrm{p}<0.001$, Fig. 3) and long-term rerevascularization (IRR $=0.37,95 \% \mathrm{Cl} 0.30 ; 0.47, \mathrm{p}<0.001$, Fig. 4). No significant difference was found in long-term myocardial infarction (IRR $=0.96$, 95\% Cl 0.50; 1.84, $p=0.61$, Supplementary Fig. 4) and peri-operative mortality (OR = 1.36, 95\% Cl 0.94; 1.95, $p=0.10$ Supplementary Fig. 5).

\section{Meta-regression}


At meta-regression, the year of publication and the proportion of patients with prior PCl were inversely associated with the IRR for the primary outcome (beta $=-0.07, p=0.01$ and beta $=-0.05, p=0.004$, respectively). The proportion of 1-vessel disease was associated with the IRR for the primary outcome (beta $=0.01, p=0.04$, Supplementary Table 5). That means that recent studies and studies with higher percentage of patients with prior PCI reported lower long-term mortality in the CABG group; and studies with higher percentage of patients with 1-vessel disease reported lower long-term mortality in the $\mathrm{PCl}$ group.

\section{Discussion}

Our analysis suggests that for the treatment of NSTE-ACS, CABG and PCI are similar with respect to long-term mortality and myocardial infarction rates. The analysis further suggests that CABG is associated with decreased rates of long-term MACE and re-revascularization.

This is the first meta-analysis to address this important topic; our results are relevant as a substantial number of patients worldwide present with NSTE-ACS every year; in Germany over a period of 10 years 2.77 million cases of NSTE-ACS were recorded[1]. In the United States there are more than 1 million hospitalizations per year due to acute coronary syndrome [12], with the proportion of patients with non-ST-elevation myocardial infarction being over $50 \%$ of all infarctions and increasing over time [2]. In other studies the annual incidence of NSTE-ACS has been reported with 88 per 100000 inhabitants [13].

Previous studies have suggested that an invasive strategy might be superior to a conservative one[3, 14], but have not summarized a recommendation for a specific invasive therapy (PCI or CABG). Currently, only $4-10 \%$ of the patients with NSTE-ACS receive CABG and $30-40 \%$ of them $\mathrm{PCl}[1,15]$.

Our findings support the current guidelines, where no clear recommendation for PCI or CABG is given and a suggestion that the criteria applied for patients with stable coronary artery disease should be applied to stabilized patients with NSTE-ACS is made [4]. Both American and European guidelines recommend a heart-team approach to revascularization decisions in NSTE-ACS $[4,16]$ and that, factors such as extent and complexity of the coronary artery disease, as well as other factors should be considered.

It has been proposed that the survival benefit of $\mathrm{PCl}$ or $\mathrm{CABG}$ may be primarily due to an infarct-preventing mechanism rather than to revascularization per se $[17,18]$. This theory might provide a mechanistical explanation of our results, showing no mortality difference in 2 invasive treatments treating the same acute events. This line of argumentation finds supports in a meta-analysis we performed demonstrating an association of a survival advantage of CABG over PCl only in cases when there was also a difference in the rate of myocardial infarction [19].

\section{STUDY STRENGTH AND LIMITATIONS}

This is the first meta-analysis to address this important topic. Moreover, we analyzed 5 different outcomes and performed different subgroup analyses and a meta-regression of 14 different pre-operative factors. However, this work has the intrinsic limitations of observational series, including the risk of methodological heterogeneity of the included studies, residual confounders and ecological fallacy of meta-regression. In addition, treatment allocation bias is likely present in all observational series comparing two interventions with different operative risk and invasiveness.

\section{Conclusion}

Our analysis suggests that for the treatment of NSTE-ACS, CABG and PCl are similar with respect to long-term mortality and myocardial infarction rates. The analysis further suggests that CABG is associated with decreased rates of long-term MACE and re-revascularization. Randomized comparisons in this specific setting are necessary.

\section{Glossary Of Abbreviations}

CABG: coronary artery bypass grafting

CAD: coronary artery disease

MACE: major cardiovascular adverse events

MI: myocardial infarction

NSTE-ACS: non-ST-elevation acute coronary syndrome

NSTEMI: non-ST-elevation myocardial infarction

PCl: percutaneous coronary intervention 
UAP: unstable angina pectoris

\section{Declarations}

Acknowledgements: We thank Mr. Benjamin May for editorial assistance.

Authors contributions: HK, TC, MG and TD designed the study. MD performed the literature review in the three different libraries. HK and TC selected the studies, qualified the studies according to the risk of bias, performed the data abstraction, built the tables and organized the results. MR and NBR performed the statistical analyses. PWS, GBZ, MG and TD analyzed the data. HK, TC, NBR, MG and TD wrote the manuscript. All the authors read and approved the final version of manuscript.

Funding: None.

Conflict of interest: The authors declare that there is no conflict of interest.

Data avaibility: The datasets generated analyzed during the current study are available from the corresponding author on reasonable request.

Ethic declaration: Ethical and internal review board approval was not required for this analysis as no human or animal subjects were involved.

\section{References}

1. Neumann, J.T., et al., Temporal trends in incidence and outcome of acute coronary syndrome. Clinical Research in Cardiology, 2020: p. 1-7.

2. Khera, S., et al., Non-ST-elevation myocardial infarction in the United States: contemporary trends in incidence, utilization of the early invasive strategy, and in-hospital outcomes. Journal of the American Heart Association, 2014. 3(4): p. e000995.

3. Bavry, A.A., et al., Benefit of early invasive therapy in acute coronary syndromes: a meta-analysis of contemporary randomized clinical trials. Journal of the American College of Cardiology, 2006. 48(7): p. 1319-1325.

4. Neumann, F.-J., et al., 2018 ESC/EACTS Guidelines on myocardial revascularization. European heart journal, 2019. 40(2): p. 87-165.

5. Page, M.J., et al., The PRISMA 2020 statement: an updated guideline for reporting systematic reviews. BMJ, 2021. $372:$ p. n71.

6. Wells, G., The Newcastle-Ottawa Scale (NOS) for assessing the quality of nonrandomised studies in meta-analysis. http://www, ohri. $\mathrm{ca}$ /programs/clinical_epidemiology. oxford. htm, 2004.

7. Viechtbauer, W., Conducting meta-analyses in $R$ with the metafor package. Journal of statistical software, 2010. 36(3): p. 1-48.

8. Schwarzer, G., J.R. Carpenter, and G. Rücker, Meta-analysis with R. Vol. 4784. 2015: Springer.

9. Higgins, J.P., et al., Measuring inconsistency in meta-analyses. Bmj, 2003. 327(7414): p. 557-60.

10. Liberati, A., et al., The PRISMA statement for reporting systematic reviews and meta-analyses of studies that evaluate health care interventions: explanation and elaboration. Journal of clinical epidemiology, 2009. 62(10): p. e1-e34.

11. Hutton, B., et al., The PRISMA extension statement for reporting of systematic reviews incorporating network meta-analyses of health care interventions: checklist and explanations. Annals of internal medicine, 2015. 162(11): p. 777-784.

12. Virani, S.S., et al., Heart disease and stroke statistics-2020 update: a report from the American Heart Association. Circulation, 2020. 141(9): p. e139-e596.

13. Antoniades, L., et al., Epidemiology of acute coronary syndromes in the Mediterranean island of Cyprus (CYPACS study, Cyprus study of acute coronary syndromes). Hellenic J Cardiol, 2014. 55(55): p. 139-149.

14. Reaño, J.D.P., et al., A systematic review and meta-analysis on the effectiveness of an invasive strategy compared to a conservative approach in patients> 65 years old with non-ST elevation acute coronary syndrome. PloS one, 2020. 15(2): p. e0229491.

15. Ranasinghe, I., et al., Risk stratification in the setting of non-ST elevation acute coronary syndromes 1999-2007. The American journal of cardiology, 2011. 108(5): p. 617-624.

16. Amsterdam, E.A., et al., 2014 AHA/ACC guideline for the management of patients with non-ST-elevation acute coronary syndromes: a report of the American College of Cardiology/American Heart Association Task Force on Practice Guidelines. Journal of the American College of Cardiology, 2014. 64(24): p. e139-e228.

17. Doenst, T. and H. Sigusch, Surgical collateralization: The hidden mechanism for improving prognosis in chronic coronary syndromes. The Journal of Thoracic and Cardiovascular Surgery, 2020.

18. Doenst, T., et al., PCl and CABG for treating stable coronary artery disease: JACC review topic of the week. Journal of the American College of Cardiology, 2019. 73(8): p. 964-976.

19. Gaudino, M., et al., Difference in spontaneous myocardial infarction and mortality in percutaneous versus surgical revascularization trials: a systematic review and meta-analysis. The Journal of Thoracic and Cardiovascular Surgery, 2021.

Page 5/10 
20. de Feyter, P.J., et al., Bypass surgery versus stenting for the treatment of multivessel disease in patients with unstable angina compared with stable angina. Circulation, 2002. 105(20): p. 2367-72.

21. Chew, D.P., et al., Patients with non-ST-elevation acute coronary syndromes undergoing coronary artery bypass grafting in the modern era of antithrombotic therapy. Am Heart J, 2008. 155(2): p. 239-44.

22. Hochholzer, W., et al., Percutaneous Coronary Intervention Versus Coronary Artery Bypass Grafting as Primary Revascularization in Patients With Acute Coronary Syndrome. The American Journal of Cardiology, 2008. 102(2): p. 173-179.

23. AlHabib, K.F., et al., Prevalence, predictors, and outcomes of conservative medical management in non-ST-segment elevation acute coronary syndromes in Gulf RACE-2. Angiology, 2012. 63(2): p. 109-18.

24. Roe, M.T., et al., Long-term outcomes after invasive management for older patients with non-ST-segment elevation myocardial infarction. Circ Cardiovasc Qual Outcomes, 2013. 6(3): p. 323-32.

25. Buszman, P.E., et al., Comparison of Stenting and Surgical Revascularization Strategy in Non-ST Elevation Acute Coronary Syndromes and Complex Coronary Artery Disease (from the Milestone Registry). American Journal of Cardiology, 2014. 114(7): p. 979-987.

26. Ben-Gal, Y., et al., Surgical versus percutaneous coronary revascularization for multivessel disease in diabetic patients with non-ST-segmentelevation acute coronary syndrome: analysis from the Acute Catheterization and Early Intervention Triage Strategy trial. Circ Cardiovasc Interv, 2015. 8(6).

27. Kurlansky, P., et al., Coronary Artery Bypass Graft Versus Percutaneous Coronary Intervention. Circulation, 2016. 134(17): p. 1238-1246.

28. Chang, M., et al., Comparison of Outcome of Coronary Artery Bypass Grafting Versus Drug-Eluting Stent Implantation for Non\&\#x2013;STElevation Acute Coronary Syndrome. American Journal of Cardiology, 2017. 120(3): p. 380-386.

29. Freitas, P., et al., Coronary Artery Bypass Grafting Versus Percutaneous Coronary Intervention in Patients With Non\&\#x2013;ST-Elevation Myocardial Infarction and Left Main or Multivessel Coronary Disease. American Journal of Cardiology, 2019. 123(5): p. 717-724.

30. Huckaby, L.V., et al., Revascularization following non-ST elevation myocardial infarction in multivessel coronary disease. J Card Surg, 2020. 35(6): p. 1195-1201.

31. Jia, S., et al., Comparison of Percutaneous Coronary Intervention, Coronary Artery Bypass Grafting and Medical Therapy in Non-ST Elevation Acute Coronary Syndrome Patients With 3-Vessel Disease. Circ J, 2020. 84(10): p. 1718-1727.

32. Ram, E., et al., Outcomes of different revascularization strategies among patients presenting with acute coronary syndromes without ST elevation. The Journal of Thoracic and Cardiovascular Surgery, 2020. 160(4): p. 926-935.e6.

\section{Tables}

Table 1. Studies included in the meta-analysis. 


\begin{tabular}{|c|c|c|c|c|c|c|c|}
\hline STUDY & STUDY DESIGN & $\begin{array}{l}\text { DEMOGRAPHICS } \\
\text { COMPARABILITY }\end{array}$ & COUNTRY & $\begin{array}{l}\text { PATIENTS } \\
\text { SYNDROM } \\
\text { INCLUDED }\end{array}$ & $\begin{array}{l}\text { № } \\
\text { PATIENTS }\end{array}$ & $\begin{array}{l}\text { ENDPOINTS } \\
\text { INCLUDED }\end{array}$ & $\begin{array}{l}\text { MEAN } \\
\text { FOLLOW- } \\
\text { UP (Y) }\end{array}$ \\
\hline $\begin{array}{l}\text { DE FEYTER, } \\
2002[20]\end{array}$ & $\begin{array}{l}\text { PRESPECIFIED ANALYSIS - } \\
\text { ARTS TRIAL }\end{array}$ & UNADJUSTED & NETHERLANDS & $\begin{array}{l}\text { UNSTABLE } \\
\text { ANGINA }\end{array}$ & 450 & $\begin{array}{l}\text { MORTI, } \\
\text { MACE, MI, } \\
\text { RR }\end{array}$ & 1 \\
\hline $\begin{array}{l}\text { CHEW, } \\
2008[21]\end{array}$ & $\begin{array}{l}\text { POST-HOC ANALYSIS - } \\
\text { SYNERGY TRIAL }\end{array}$ & UNADJUSTED & AUSTRALIA & $\begin{array}{l}\text { UNSTABLE } \\
\text { ANGINA } \\
\text { AND } \\
\text { NSTEMI }\end{array}$ & 9902 & MORTI, MI & 0.5 \\
\hline $\begin{array}{l}\text { HOCHHOLZER, } \\
2008[22]\end{array}$ & $\begin{array}{l}\text { PROSPECTIVE COHORT } \\
\text { STUDY }\end{array}$ & $\begin{array}{l}\text { MULTIVARIABLE } \\
\text { REGRESSION }\end{array}$ & GERMANY & $\begin{array}{l}\text { UNSTABLE } \\
\text { ANGINA } \\
\text { AND } \\
\text { NSTEMI }\end{array}$ & 1024 & MORTI, MI & 1.3 \\
\hline $\begin{array}{l}\text { ALHABIB, } \\
2012[23]\end{array}$ & $\begin{array}{l}\text { PROSPECTIVE STUDY - } \\
\text { GULF RACE-2 REGISTRY }\end{array}$ & UNADJUSTED & SAUDI ARABIA & $\begin{array}{l}\text { UNSTABLE } \\
\text { ANGINA } \\
\text { AND } \\
\text { NSTEMI }\end{array}$ & 802 & $\begin{array}{l}\text { MORTp, } \\
\text { MORTI }\end{array}$ & 1 \\
\hline ROE, 2013 [24] & $\begin{array}{l}\text { RETROSPECTIVE - CRUSADE } \\
\text { REGISTRY }\end{array}$ & UNADJUSTED & $\begin{array}{l}\text { UNITED } \\
\text { STATES }\end{array}$ & NSTEMI & 15281 & $\begin{array}{l}\text { MORTI, } \\
\text { MACE, RR }\end{array}$ & 3.2 \\
\hline $\begin{array}{l}\text { BUSZMAN, } \\
2014 \text { [25] }\end{array}$ & $\begin{array}{l}\text { PROSPECTIVE STUDY- } \\
\text { MILESTONE REGISTRY }\end{array}$ & $\begin{array}{l}\text { PROPENSITY } \\
\text { SCORE } \\
\text { MATCHING }\end{array}$ & POLAND & $\begin{array}{l}\text { UNSTABLE } \\
\text { ANGINA } \\
\text { AND } \\
\text { NSTEMI }\end{array}$ & 4566 & $\begin{array}{l}\text { MORTp, } \\
\text { MORTI }\end{array}$ & 3 \\
\hline $\begin{array}{l}\text { BEN-GAL, } \\
2015[26]\end{array}$ & $\begin{array}{l}\text { POST-HOC ANALYSIS - } \\
\text { ACUITY TRIAL }\end{array}$ & $\begin{array}{l}\text { PROPENSITY } \\
\text { SCORE } \\
\text { MATCHING }\end{array}$ & ISRAEL & $\begin{array}{l}\text { UNSTABLE } \\
\text { ANGINA } \\
\text { AND } \\
\text { NSTEMI }\end{array}$ & 1772 & $\begin{array}{l}\text { MORTp, } \\
\text { MORTI, } \\
\text { MACE, MI, } \\
\text { RR }\end{array}$ & 1 \\
\hline $\begin{array}{l}\text { KURLANSKY, } \\
2016[27]\end{array}$ & $\begin{array}{l}\text { RETROSPECTIVE - CARE } \\
\text { REGISTRY }\end{array}$ & $\begin{array}{l}\text { PROPENSITY } \\
\text { SCORE } \\
\text { MATCHING }\end{array}$ & $\begin{array}{l}\text { UNITED } \\
\text { STATES }\end{array}$ & NSTEMI & 3228 & MACE & $\begin{array}{l}5.6 \\
(\mathrm{CABG}) \\
\text { AND 5.1 } \\
(\mathrm{PCI})\end{array}$ \\
\hline $\begin{array}{l}\text { CHANG, } \\
2017 \text { [28] }\end{array}$ & $\begin{array}{l}\text { PATIENT LEVEL DATA- } \\
\text { BEST/PRECOMBAT/SYNTAX }\end{array}$ & UNADJUSTED & SOUTH KOREA & $\begin{array}{l}\text { UNSTABLE } \\
\text { ANGINA } \\
\text { AND } \\
\text { NSTEMI }\end{array}$ & 1246 & $\begin{array}{l}\text { MORTI, } \\
\text { MACE, MI, } \\
\text { RR }\end{array}$ & 5 \\
\hline $\begin{array}{l}\text { FREITAS, } \\
2019[29]\end{array}$ & $\begin{array}{l}\text { PROSPECTIVE } \\
\text { OBSERVATIONAL STUDY }\end{array}$ & $\begin{array}{l}\text { MULTIVARIABLE } \\
\text { REGRESSION }\end{array}$ & PORTUGAL & NSTEMI & 688 & MORTI & 4.8 \\
\hline $\begin{array}{l}\text { HUCKABY, } \\
2020[30]\end{array}$ & RETROSPECTIVE & $\begin{array}{l}\text { MULTIVARIABLE } \\
\text { REGRESSION }\end{array}$ & $\begin{array}{l}\text { UNITED } \\
\text { STATES }\end{array}$ & NSTEMI & 2001 & $\begin{array}{l}\text { MORTI, } \\
\text { MACE, MI, } \\
\text { RR }\end{array}$ & 3.6 \\
\hline JIA, 2020 [31] & $\begin{array}{l}\text { PROSPECTIVE } \\
\text { OBSERVATIONAL STUDY }\end{array}$ & $\begin{array}{l}\text { MULTIVARIABLE } \\
\text { REGRESSION }\end{array}$ & CHINA & $\begin{array}{l}\text { UNSTABLE } \\
\text { ANGINA } \\
\text { AND } \\
\text { NSTEMI }\end{array}$ & 2819 & $\begin{array}{l}\text { MORTI, } \\
\text { MACE, MI, } \\
\text { RR }\end{array}$ & 7.5 \\
\hline \multirow{2}{*}{$\begin{array}{l}\text { RAM, } \\
2020 \text { [32] }\end{array}$} & PROSPECTIVE STUDY - & \multirow{2}{*}{$\begin{array}{l}\text { MULTIVARIABLE } \\
\text { REGRESSION }\end{array}$} & \multirow[t]{2}{*}{ ISRAEL } & \multirow{2}{*}{$\begin{array}{l}\text { UNSTABLE } \\
\text { ANGINA } \\
\text { AND } \\
\text { NSTEMI }\end{array}$} & \multirow[t]{2}{*}{5112} & \multirow{2}{*}{$\begin{array}{l}\text { MORTp, } \\
\text { MORTI }\end{array}$} & \multirow[t]{2}{*}{3} \\
\hline & ACSIS REGISTRY & & & & & & \\
\hline
\end{tabular}

$\mathrm{CABG}=$ coronary artery bypass grafting; $\mathrm{MACE}=$ major adverse cardiovascular events; $\mathrm{Ml}=$ myocardial infarction; $\mathrm{MORTI=} \mathrm{long-term} \mathrm{mortality;}$ MORTp= peri-operative mortality; NSTEMI=non-ST-elevation myocardial infarction; $\mathrm{PCl}=$ percutaneous coronary intervention, RR=rerevascularization.

Table 2. Outcomes summary. 


\begin{tabular}{|c|c|c|c|c|}
\hline Outcome & Studies No. & Patients No. & Effect Estimate $(95 \% \mathrm{Cl}), \mathrm{p}$-value & Heterogeneity (礼, p-value) \\
\hline Long-term mortality & 12 & 26725 & $\mathrm{IRR}=0.93[0.70 ; 1.23], \mathrm{p}=0.61$ & $88.1 \%, p<0.001$ \\
\hline Long-term MACE & 7 & 24519 & $\mathrm{IRR}=0.64[0.54 ; 0.76], p<0.001$ & $77.4 \%, p<0.001$ \\
\hline Long-term re-revascularization & 6 & 22573 & IRR=0.37 [0.30; 0.47], $p<0.001$ & $42.7 \%, p=0.11$ \\
\hline Long-term myocardial infarction & 7 & 7572 & $\mathrm{IRR}=0.96[0.50 ; 1.84], \mathrm{p}=0.61$ & $93.0 \%, p<0.001$ \\
\hline Peri-operative mortality & 5 & 4334 & $\mathrm{OR}=1.36[0.94 ; 1.95], p=0.10$ & $60.0 \%, p=0.83$ \\
\hline
\end{tabular}

IRR= incidence rate ratio; $\mathrm{MACE}=$ major adverse cardiovascular events; $\mathrm{No}=$ number; $\mathrm{OR}=$ odds ratios

\section{Figures}
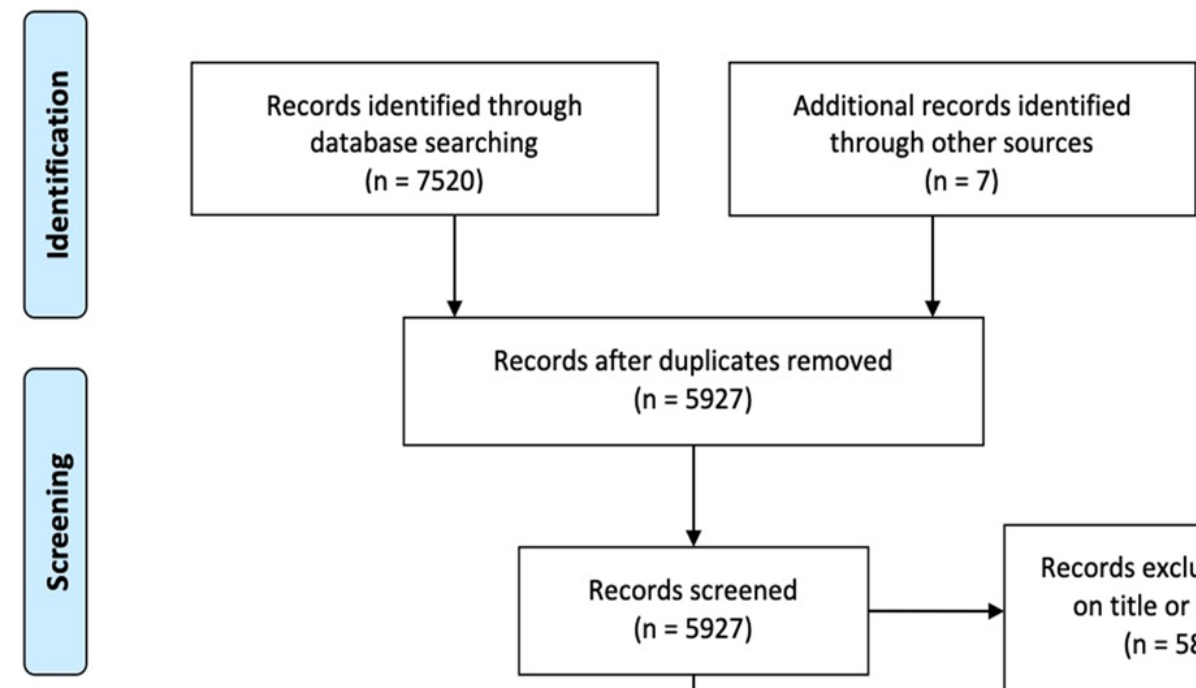

Records after duplicates removed

$(n=5927)$
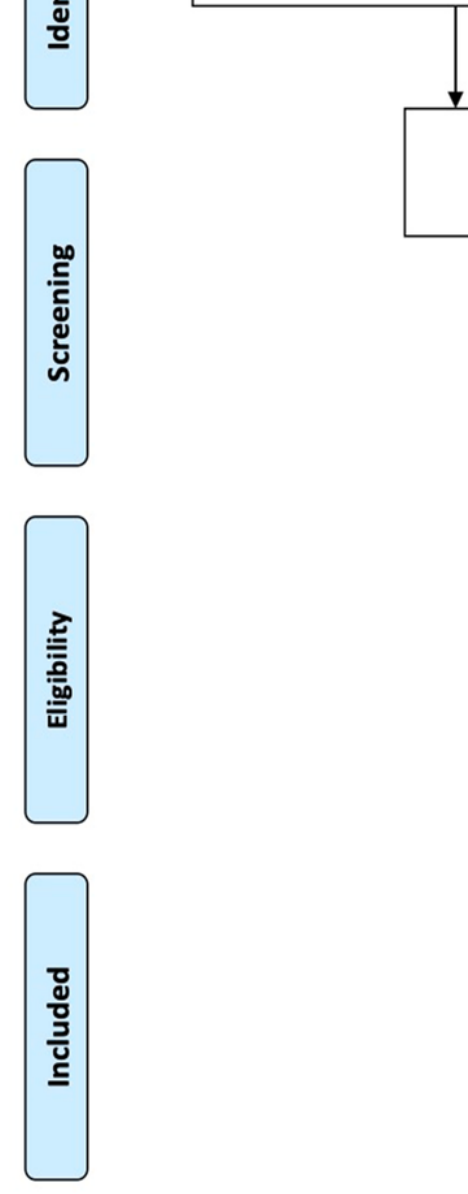

Studies included in

Records excluded based on title or abstract $(n=5851)$

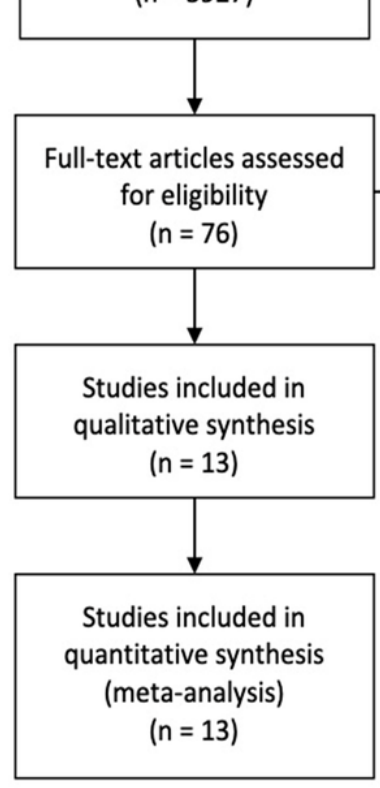

\section{Figure 1}

PRISMA Flow Diagram. Preferred Reporting Items for Systematic Reviews and Meta-Analyses flow diagram. 


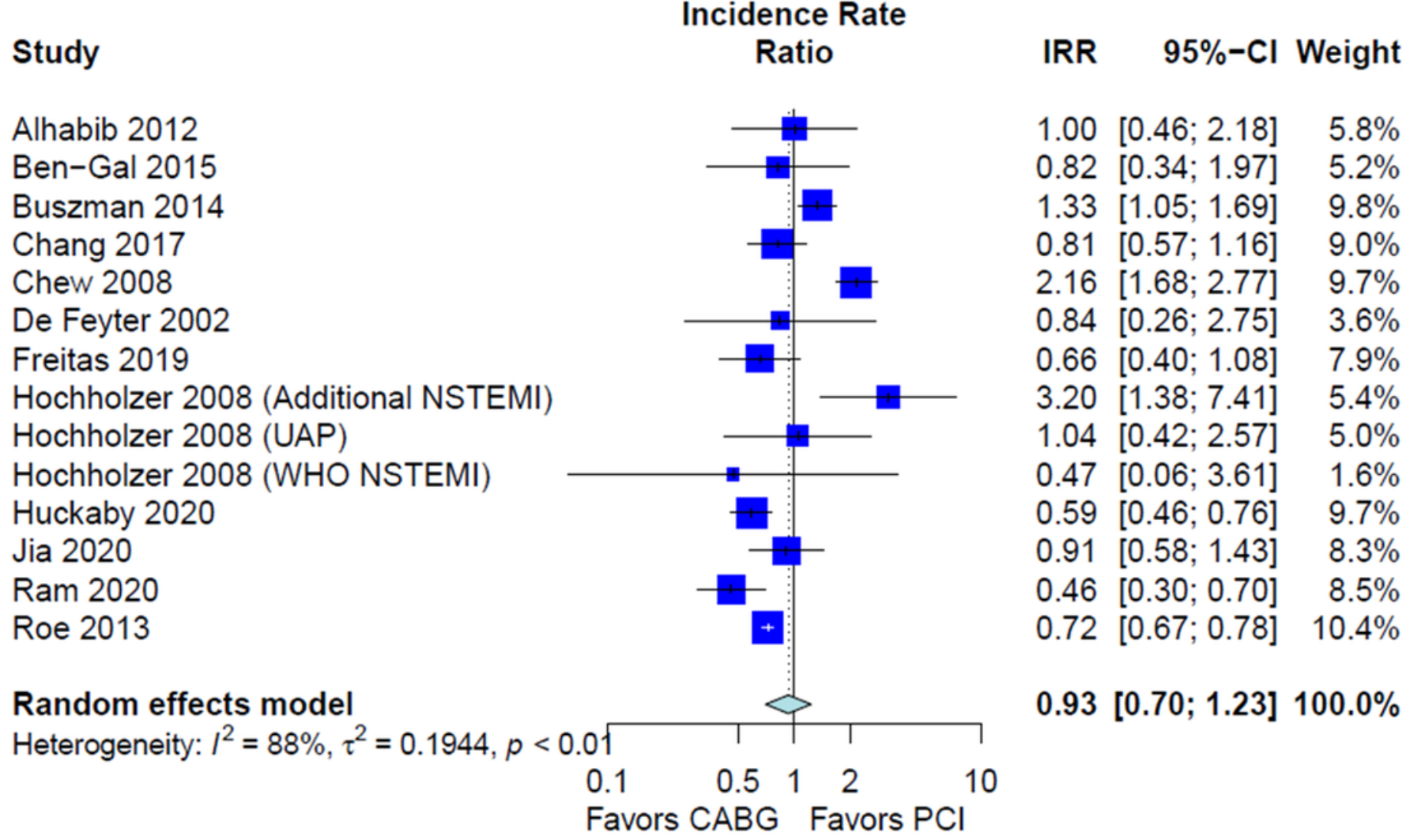

Figure 2

Forest plot for long-term mortality. Forest plot showing pooled rates of long-term mortality in patients with non-ST-elevation acute coronary syndrome (NSTE-ACS) treated with coronary artery bypass grafting (CABG) or percutaneous coronary intervention (PCI). Abbreviations: $\mathrm{CABG}=$ coronary artery bypass grafting, $\mathrm{Cl}=$ confidence interval, IRR= incidence rate ratio, NSTEMI= non-ST-elevation myocardial infarction, $\mathrm{PCl}=$ percutaneous coronary intervention, $\mathrm{UAP}=$ unstable angina pec-toris, $\mathrm{WHO}=$ world health organization.

\section{Study}

Ben-Gal 2015

Chang 2017

De Feyter 2002

Huckaby 2020

Jia 2020

Kurlansky 2016 (Optimal Medical Therapy)

Kurlansky 2016 (Not Optimal Medical Therapy)

Roe 2013

\section{Random effects model}

Heterogeneity: $I^{2}=77 \%, \tau^{2}=0.0410, p<0.01$

\section{Incidence Rate}

Ratio

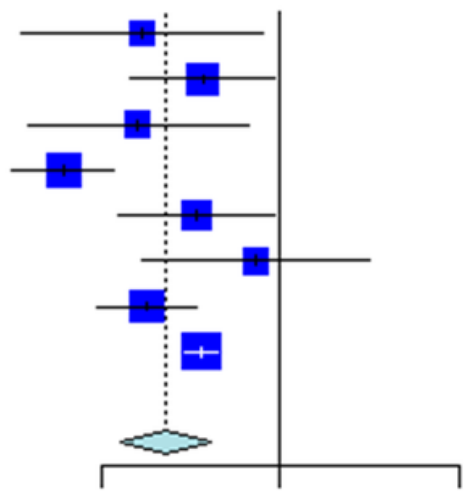

$\begin{array}{lll}0.5 & 1 & 2\end{array}$

Favors CABG Favors $\mathrm{PCl}$
IRR $\quad 95 \%-\mathrm{Cl}$ Weight

$0.58[0.37 ; 0.93] \quad 8.1 \%$

$0.74[0.56 ; 0.98] \quad 12.8 \%$

$0.57[0.37 ; 0.88] \quad 8.9 \%$

$0.43[0.35 ; 0.52] \quad 15.4 \%$

$0.72[0.53 ; 0.97] \quad 12.1 \%$

$0.91[0.58 ; 1.41] \quad 8.6 \%$

$0.60[0.49 ; 0.72] \quad 15.4 \%$

$0.73[0.69 ; 0.78] \quad 18.7 \%$

$0.64[0.54 ; 0.76] 100.0 \%$ 


\section{Study}

Ben-Gal 2015

Chang 2017

De Feyter 2002 (New CABG)

De Feyter 2002 (New PCl)

Huckaby 2020

Jia 2020

Roe 2013

Random effects model

Heterogeneity: $I^{2}=43 \%, \tau^{2}=0.0327, p=0.11$

\section{Incidence Rate} Ratio

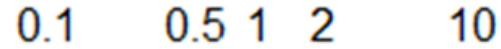

\section{IRR $\quad 95 \%-\mathrm{Cl}$ Weight}

$\begin{array}{rlr}0.27 & {[0.12 ; 0.58]} & 7.1 \% \\ 0.56[0.41 ; 0.76] & 23.9 \% \\ 0.14[0.03 ; 0.63] & 2.2 \% \\ 0.25[0.10 ; 0.62] & 5.6 \% \\ 0.34[0.21 ; 0.55] & 14.6 \% \\ 0.33[0.17 ; 0.64] & 9.4 \% \\ 0.36[0.32 ; 0.41] & 37.2 \%\end{array}$

$0.37[0.30 ; 0.47] 100.0 \%$

Figure 4

Forest plot for long-term re-revascularization. Forest plot showing pooled rates of long-term re-revascularization in patients with non-ST-elevation acute coronary syndrome (NSTE-ACS) treated with coronary artery bypass grafting (CABG) or percutaneous coronary intervention (PCI).

Abbreviations: $\mathrm{CABG}=$ coronary ar-tery bypass grafting, $\mathrm{Cl}=$ confidence interval, $\mathrm{IRR}=$ incidence rate ratio, $\mathrm{PCl}=$ percutaneous coronary intervention.

\section{Supplementary Files}

This is a list of supplementary files associated with this preprint. Click to download.

- NSTEACSMASupplementaryMaterial.docx

- PRISMA2020checklist.pdf

- GraphicalAbstract.png 